Immunology

Manuscript Number:

Title: DUAL ROLE OF COMPLEMENT IN ADIPOSE TISSUE

Article Type: Review Article

Section/Category:

Keywords: adipocyte; metabolism; immune defense; complement.

Corresponding Author: Dr. Cordula Stover, Dr.med, PhD

Corresponding Author's Institution: University of Leicester

First Author: Michael Pattrick

Order of Authors: Michael Pattrick; Jeni Luckett, PhD; Liang Yue, MSc; Cordula Stover, Dr.med, PhD; Cordula M Stover, Dr.med., PhD

Manuscript Region of Origin: 


\begin{abstract}
Once thought of as purely the body's chief energy store, adipose tissue and its constituent adipocytes have emerged as both a metabolic entity and an endocrine one. Complement is generally thought of as originating mainly from hepatic synthesis but also from synthesis by the macrophage phagocyte system. This review revisits early descriptions of adipocytic synthesis of complement components and highlights the need of a systematic analysis of the contribution of adipose tissue to systemic inflammation in order to appreciate the immunological activity of this tissue.
\end{abstract}




\title{
REVIEW:
}

\section{DUAL ROLE OF COMPLEMENT IN ADIPOSE TISSUE}

Michael Pattrick, Jeni Luckett, Liang Yue and Cordula Stover*

Dept. of Infection, Immunity and Inflammation, University of Leicester, University Road, Leicester LE $19 \mathrm{HN}$

* Corresponding author: Dr. med. Cordula M. Stover, PhD; Dept. of Infection, Immunity and Inflammation, University of Leicester, University Road, Leicester LE 19HN, email cms13@le.ac.uk, tel ++44-116-2525032, fax ++44-116-2525030

\begin{abstract}
Once thought of as purely the body's chief energy store, adipose tissue and its constituent adipocytes have emerged as both a metabolic entity and an endocrine one. Complement is generally thought of as originating mainly from hepatic synthesis but also from synthesis by the macrophage phagocyte system. This review revisits early descriptions of adipocytic synthesis of complement components and highlights the need of a systematic analysis of the contribution of adipose tissue to systemic inflammation in order to appreciate the immunological activity of this tissue.
\end{abstract}

Key words: adipocyte, metabolism, immune defense, complement 


\section{Introduction}

For simplicity's sake, complement is generally described in terms of its function within the innate immune defence. There it acts as a concept fulfilling humoral system of pattern recognition and pattern-mediated activation, contributing in its own right to adaptive immunity.

The classical pathway of complement is initiated by the recognition of immune complexes but also by interaction of the multimeric, basic, $\mathrm{C} 1 \mathrm{q}$ with negatively charged molecules such as DNA, LPS, and histones. This interaction effects activation of associated serine proteases which mediate cleavage and thereby activation of complement component C4 (figure 1). C4b bound C2 acquires substrate specificity for $\mathrm{C} 3$, generating $\mathrm{C} 3 \mathrm{~b}$ and $\mathrm{C} 3 \mathrm{a}$, one of the anaphylatoxins of complement. After assembly of the $\mathrm{C} 4 \mathrm{~b} 2 \mathrm{a} 3 \mathrm{~b}$ complex, complement component $\mathrm{C} 5$ is cleaved and activated in a last enzymatic step. The generated C5b inserts into the target membrane and then assembles with C6, 7, 8, 9 to form the membrane attack complex. For this to remain localised, ester and amid, covalent, bonds are formed by C4 and C3 with residues on target surfaces, and host regulators are present, either surface bound or soluble, that maintain a balance. Any circulating immune complex is captured by CR 1 in sinusoidal reticulum of the liver.

Complement is also activated via the lectin pathway, namely the recognition of surface carbohydrates of micro-organisms, using pattern recognition molecules MBL and Ficolin which are associated with specific serine proteases, of which MASP-2 directly mediates C4 cleavage. Activation then continues as described above and is thought to be efficient in the defence against gram-negative bacteria. Microorganisms are coated by C3b and thereby tagged for uptake by macrophages, however, in some instances, this process can actually provide the mechanism of entry for intracellular organisms. 
The alternative pathway of complement has its own specific C3 converting enzyme complex, $\mathrm{C} 3 \mathrm{bBb}$, which is formed when generated $\mathrm{C} 3 \mathrm{~b}$ associates with Factor $\mathrm{D}$ cleaved Factor B. Subsequent, additional association of C3b then gives rise to the C5 converting enzyme complex, $\mathrm{C}_{3} \mathrm{~b}_{\mathrm{n}} \mathrm{Bb}$, which generates $\mathrm{C} 5 \mathrm{~b}$ and $\mathrm{C} 5 \mathrm{a}$.

The membrane attack complex disrupts membranes of those bacteria that do not possess a thick wall, so generation of anaphylatoxins to attract leukocytes and C3 products to interface with the adaptive immune response (by influencing antibody secretion by B-cells) is thought to be relatively more important in the defence of gram positive or encapsulated organisms.

However, complement also has a role in reproductive success (Harris et al., 2006), embryonic implantation (Bulla et al., 2005), and tissue regeneration (Mastellos et al., 2005) that seems well removed from any infectious or inflammatory process per se. In principle, the connection between complement and adipose tissue has a long history. Lipodystrophy was found to coincide with hypocomplementemia (Sissons et al., 1976), prior to first descriptions of familial C3 deficiency presenting with partial lipodystrophy (McLean and Hoefnagel, 1980). This review is concerned with summarising knowledge gained since the early description of C3adesArg, the carboxypeptidase-modified anaphylatoxin $\mathrm{C} 3 \mathrm{a}$ (lacking the $\mathrm{C}$-terminal arginine residue and therefore any ability to signal via C3aR) as a peptide involved in triglyceride synthesis (Baldo et al., 1993). Of note, based on its inability to bind to C3aR, C3adesarg is not implied in the activation and proliferation processes characteristic of atherosclerotic changes (Verdeguer et al., 2007). We will aim to contextualise the role complement in relation to a recently recognised endocrine (Miner, 2004) and immune (Fantuzzi et al., 2005) role of adipose tissue. The focus will be on white adipose tissue, which preferentially expresses complement factors, contrasting with thermoregulatory brown adipose tissue (Boeuf et al., 2001). 


\section{Adipose tissue, origin and role in metabolism}

Adipocytes, like other connective tissue cells, are derived from fibroblast-like precursor stem cells in bone marrow that can differentiate into many types of connective tissue cells. The differentiation of adipocytes is governed by two gene regulating families of proteins, the CEBP (CCAT/enhancer protein) and PPAR (peroxisome proliferating activating receptor - in particular PPAR $\gamma$ ) families. These two families are intricately involved with each other with feedback loops governing each other's expression as well as being involved in the expression of other proteins specific to adipocytes.

Once adipocytes have differentiated from their common precursor cells, membrane proteins and enzymes are produced that serve to move lipids into the cells.

Simultaneously, lipases are formed that allow for reversion of the process of lipid invasion should energy be needed elsewhere in the body.

The bulk of adipose tissue in humans is made up of unilocular white adipose tissue. Histologically this is made up of adipocytes resembling a signet ring with one large, centrally placed lipid droplet. Adipocytes -spherical in isolation- become polyhedral when tightly packed to allow for an increased number of cells per unit of space. Adipocytes have a thin cytoplasm that surrounds the lipid droplet and is thickened at the eccentrically placed nucleus and the cisternae of the rough endoplasmic reticulum. White adipose tissue is found subcutaneously all over the body and also surrounds the viscera and makes up the palm and feet fat pads as well as the periorbital fat. In contrast, multilocular brown adipose tissue is not as evenly distributed and has a different histological appearance. It includes more than one lipid droplet and an increased number of mitochondria. The cells are smaller and polygonal with centrally placed nuclei. At birth, brown adipose tissue can be found around the heart and in areas around the scapula where it plays an important role in temperature homeostasis. With 
ageing, the amount of brown adipose tissue reduces and it comes to reside as discrete islands within white adipose tissue.

A major role of white adipose tissue is as an energy store. Energy from food is not in constant supply so at times when intake exceeds expenditure, energy is stored for use at a later time. Following ingestion and digestion by pancreatic lipase in the small intestine, triaclyglycerides (TAGs) are packaged into chylomicrons by small intestine enterocytes. For efficient transport around the body, TAGs along with cholesterol esters form the core of the chylomicron whilst apolipoproteins, cholesterol and phospholipids form the external layer. Once packaged, chylomicrons are transported via mesenteric lymphatic channels to the adipose tissue. Under stimulation by hormones, such as insulin, lipoprotein lipase hydrolyses the TAGs to release fatty acids. These fatty acids are transported from the blood capillaries into the adipocytes before being repackaged with glycerol to form TAGs once again. TAGs are then added to the central lipid droplet forming the adipose tissue. Under times of stress and when energy expenditure is higher than intake, the adipose tissue serves as a source of energy. Under influence from the sympathetic nervous system, energy is mobilised by the enzyme hormone sensitive lipase. TAGs are hydrolysed with the remaining fatty acid chain broken down stepwise, releasing acetyl CoA to enter the energy cycle and ultimately produce ATP.

Brown adipose tissue plays a different role. The inner mitochondrial membranes of the brown adipocytes contain a protein known as uncoupling protein. This protein functions to uncouple electron transport from ATP synthesis by providing an alternative route for protons other than ATP synthase available in other cells. The so-called proton motive force is dissipated as heat, which can then be transferred elsewhere into the body. It forms an important part of non-shivering thermogenesis and is especially important in hibernating animals and in newborn humans who are susceptible to heat loss. 


\section{Adipokines}

Adipose tissue contributes to the pool of circulating inflammatory mediators (Tilg and Moschen, 2006). These so-called adipokines include cytokines, chemokines, vasoactive substances, growth factors and acute phase reactants (Trayhurn 2005). Adipose tissue derived nitric oxide, another component of the immune response, is increased in experimental endotoxemia (Kapur et al., 1999). Other adipose tissue derived molecules, which are found to increase on systemic inflammation, are calcitonin peptides (Linscheid et al., 2005) and somatostatin (Seboek et al., 2004), both neuroendocrine molecules. Other molecules have been described as originating from white adipose tissue, such as leptin, adiponectin and visfatin, but were subsequently found to be expressed elsewhere (to include immune and nonimmune cells) and to exhibit additional, immune modulatory functions.

Leptin is produced by adipocytes, travels in the blood stream to access the circumventricular organs where it stimulates receptors in, among other places, the arcuate nucleus in the mediobasal hypothalamus. It represses food intake by promoting anorexigenic pathways as well as increasing energy expenditure. Leptin functions to modulate neuropeptide $Y$ that is a potent stimulator of food intake. These two actions compliment each other and serve to reduce the amount of energy that is converted to storage in adipose tissue. Circulating leptin also serves to increase insulin sensitivity. A role for leptin in the immune response has been deduced from leptin deficient mice that showed thymic atrophy (Howard et al., 1999).

Adiponectin is an insulin-sensitizing agent that acts to enhance glucose stimulated insulin secretion and has anti-inflammatory effects by stimulating production of II- 10 . Visfatin is produced by visceral fat stores and binds to and activates the insulin receptor. Visfatin induces chemotaxis and production of TNF- $\alpha$ and II-6, potent inflammatory cytokines. 


\section{Role of complement in homoiostasis and immune defense of adipose tissue}

C3adesArg, initially characterised as ASP, acylation stimulating protein, is produced by adipocytes and has, via its binding to C5L2, a role in triglyceride synthesis (Kalant et al., 2003). ASP is increased following a fatty meal and is decreased in fasting. ASP stimulates the production of TAGs (Murray et al., 1999). Via binding of ASP to a Gprotein coupled receptor C5L2 and activation of phospholipase C, calcium-dependent protein kinase $\mathrm{C}$ is activated (figure 2). Furthermore, C3adesarg stimulates preadipocyte differentiation in vitro, measured as triglyceride accumulation, increase of differentiation-related transcription factors, and cell cycle synchronisation (Maslowska et al., 2005). There are several proposed pathways for the intracellular signalling pathway used by ASP (Maslowska et al., 2006). Of note, they are all insulin independent. Importantly, adipose tissue produces C3, Factor B and Factor D, factors necessary for the provision of $\mathrm{C} 3 \mathrm{a}$. Carboxypeptidase $\mathrm{N}$ is the exopeptidase that generates C3adesarg (and C3adesargdeslys) from C3a, and is constitutively expressed. Carboxypeptidase R, a more recently characterised exopeptidase that generates solely C3adesarg, is produced as a pro-enzyme and is regulated as an acute phase protein (Sato et al., 2000), counter-balancing over-inflammation by precluding binding of C3a to C3aR. To assess whether carboxypeptidase $\mathrm{N}$ as regulator of $\mathrm{C} 3 \mathrm{a}$ activity has a more predominant role to play in adipocyte homoeostasis, generation and analysis of a carboxypeptidase $\mathrm{N}$ - deficient mouse model is needed and has been discussed (Matthews et al., 2004).

A study analysing the role of the chemokine, MCP-1, in adipogenesis (Hemmrich et al., 2007), used as a control, zymosan, a "non-specific inflammatory stimulus". In this study, matrigel chambers supplemented with fibroblast growth factor and zymosan were implanted into mouse groin and analysed six weeks later. Macrophages had migrated into the chambers and conditions gave rise to de novo adipogenesis. Zymosan, 
however, is able to activate all three pathways of complement (Fearon and Austen, 1977; Schenkein and Ruddy, 1981; Brouwer et al., 2006), and therefore, this "control" experiment reveals important clues on the significance of the influence of complement activation on localised adipogenesis. The mechanism, however, remains unclear. Was the adipogenic effect in this study significantly enhanced by greater activation of complement and provision of C3adesarg? Or did complement activation products activate macrophages to induce transdifferentiation into adipocytes? What is the relative importance for macrophages, and indeed for adipocytes (Bès-Houtmann et al., 2007), of TLR-dependent signaling of zymosan? What reciprocal role does TNF- $\alpha$ release by adipocytes and macrophages play (Cawthorn and Sethi, 2008)?

Complement, however, must be seen in wider contextual importance, based not solely on its activation-mediated effects, but, importantly, on structural homologies components have with other protein families.

PPAR $\gamma$ is a key nuclear receptor in fat metabolism and adipocyte differentiation. After activation, PPAR $\gamma$ activates transcription of a multitude of genes, including that of thrombospondin-1, TSP-1 (Okuno et al., 2002), a molecule expressed in adipose tissue and involved in the differentiation of pre-adipocytes to adipocytes, as well as its receptor, CD36 (Lim et al., 2006), the so-called fatty acid translocase. Thrombospondin shares homology with properdin, the positive regulator of complement activation, based on conservation of certain structural, thrombospondin, repeats, TSRs, which are relevant for the binding to CD36 (figure 3). Properdin may, as C3, be tightly involved in adipocyte homoiostasis. C3adesarg is generated via the alternative pathway (Paglialunga et al., 2008), and properdin could, mechanistically, through stabilisation of the alternative pathway C3 convertase complex, ensure the provision of the C3adesArg precursor, and through binding to CD36, aid in the mediation of effects favoring differentiation to 
adipocytes. There is further support of an adipose tissue related role of properdin:

During adipocyte differentiation, synthesis of proteoglycans, which facilitate the uptake of lipoproteins, is increased. These proteoglycans are composed of chondroitin sulfate and heparan sulfate glycosaminoglycans (Wilsie et al., 2005), moieties, which have been recently shown to bind properdin (Kemper et al., 2008). In addition, properdin may fulfil within adipose tissue, independent of complement activation, its more general role of tagging apoptotic and necrotic cells (Xu et al., 2008).

The exact role of complement in the contribution of adipose tissue to immune defence is difficult to assess because the extent to which adipose tissue as a whole contributes to systemic inflammatory processes has not been explored. Equally, the extent to which complement components contribute to adipose tissue homoeostasis requires attention, taking into consideration a cellular milieu that encompasses, apart from adipocytes; mast cells, macrophages, and microvascular endothelial cells. We find properdin expressed by adipocytes and mast cells (figure 4A-C). The expression of properdin by mouse mast cells is consistent with our previous description (Stover et al., 2008) and highlights an additional need to define the significance of the immune role of adipose mast cells. Adipocytes express TLRs (and CD14) and thereby could play an active role in the innate immune system (Schäffler et al., 2007). The characterisation of a variety of complement proteins generated by adipose tissue contributes to this concept. Table 1 gives an overview of complement transcripts identified in human and mouse adipose tissues and cells. Adipokines and immune factors interact locally, as e.g. adiponectin and pentraxin, both of which bind C1q (Peake et al., 2008 and Bottazzi et al., 1997), thus interweaving different systems and effecting activation. 


\section{Conclusion}

Adipose tissue clearly has a role to play in energy storage, heat generation and insulation. More recently, adipose tissue has been identified as a large endocrine organ. The role of the adipose tissue in the immune response may be largely based on the functional overlap between macrophages and adipocytes (Wellen and Hotamisligil, 2005). As far as complement is concerned, the dual role of adipose tissue (metabolism and host defense) is echoed by the dual role complement plays in relation to adipose tissue: on the one hand local complement production provides a constituent of triglyceride synthesis, on the other hand it furnishes a local immune repertoire that can be activated during local and systemic inflammation. This dualism may be mirrored in the gene of the central complement component, $\mathrm{C} 3$, an acute phase reactant: The promoter of the C3 gene harbours estrogen-response elements (Vik et al., 1991). While there is no obvious reason why the abundance of the innate immune response should differ between the sexes, the presence of these regulatory elements may indeed more readily connect to sex-related fat metabolism.

\section{Acknowledgments}

The study was supported by the MRC (G0400300, CS). 


\section{References}

Baldo, A., Sniderman, A., St-Luce, S., Avramoglu, R.K., Maslowska, M., Hoang, B., Monge, J.C., Bell, A., Cianflone, K., 1993. The adipsin-acylation stimulating protein system and regulation of intracellular triglyceride synthesis. J. Clin. Invest. 92, 15431547.

Bès-Houtmann, S., Roche, R., Hoareau, L., Gonthier, M.P., Festy, F., Caillens, H., Gasque, P., Lefebvre d'Hellencourt Cesari, M., 2007. Presence of functional TLR2 and TLR4 on human adipocytes. Histochem Cell Biol. 127, 131-137.

Boeuf, S., Klingenspor, M., van Hal, N., Schneider, T., Keijer, J., Klaus, S., 2001. Differential gene expression in white and brown preadipocytes. Physiol. Genomics. 7, $15-25$.

Bottazzi, B., Vouret-Craviari, V., Bastone, A., De Gioia, L., Matteucci, C., Peri, G., Spreafico, F., Pausa, M., D’Ettore, C., Gianazza, E., Tagliabue, A., Salmona, M., Tedesco, F., Introna, M., Mantovani, A., 1997. Multimer formation and ligand recognition by the long pentraxin PTX3. J. Biol. Chem. 272, 32817-32823.

Brouwer, N., Dolman, K.M., van Zwieten, R., Nieuwenhuys, E., Hart, M., Aarden, L.A., Roos, D., Kuijpers, T.W., 2006. Mannan-binding lectin (MBL)-mediated opsonization is enhanced by the alternative pathway amplification loop. Mol. Immunol. 43, 2051-60. Bulla, R., Bossi, F., Fischetti, F., De Seta, F., Tedesco, F., 2005. The complement system at the fetomaternal interface. Chem. Immunol. Allergy. 89, 149-57. Cawthorn, W.P., Sethi, J.K., 2008. TNF- $\alpha$ and adipocyte biology. FEBS Letters. 582, 117-131.

Fantuzzi, G,. 2005. Adipose tissue, adipokines, and inflammation. J. Allergy Clin. Immunol. 115, 911-919.

Fearon, D.T., and Austen, K.F,. 1977. Activation of the alternative complement pathway due to resistance of zymosan-bound amplification convertase to endogenous regulatory 
mechanisms. Proc. Natl. Acad. Sci. U S A. 74, 1683-1687.

Harris, C.L., Mizuno, M., Morgan, B.P., 2006. Complement and complement regulators in the male reproductive system. Mol. Immunol. 43, 57-67.

Hemmrich, K., Thomas, G.P., Abberton, K.M., Thompson, E.W., Rophael, J.A., Penington, A.J., Morrison, W.A., 2007. Monocyte chemoattractant protein-1 and nitric oxide promote adipogenesis in a model that mimics obesity. Obesity 15, 2951- 2957. Howard, J.K., Lord, G.M., Matarese, G., Vendetti, S., Ghatei, M.A., Ritter, M.A., Lechler, R. I., Bloom, S.R., 1999. Leptin protects mice from starvation-induced lymphoid atrophy and increases thymic cellularity in ob/ob mice. J. Clin. Invest. 104, 1051-9.

Kalant, D., Cain, S., Maslowska, M., Sniderman, A., Cianflone, K., Monk, P., 2003. The chemoattractant receptor-like protein C5L2 binds the C3a des-Arg77/acetylationstimulating protein. J. Biol. Chem. 278, 11123-11129.

Kapur, S., Marcotte, B., Marette, A., 1999. Mechanism of adipose tissue iNOS induction in endotoxemia. Am. J. Physiol. 276, E635-641.

Kemper, C., Mitchell, L., Zhang, L., Hourcade, D.E., 2008. The complement protein properdin binds apoptotic T cells and promotes complement activation and Phagocytosis. Proc. Natl. Acad. Sci. USA 105, 9023-9028.

Koza, R., Nikonova, L., Hogan, J., Rim, J-S., Mendoza, T., Faulk, C., Skaf, J., Kozak, L., 2006. Changes in gene expression foreshadow diet-induced obesity in genetically identical mice. PloS Genetics. 2, e81.

Lim, H.J., Lee, S., Lee, K.S., Park, J.H., Lee, EJ., Park HY., 2006. PPARgamma activation induced CD36 expression and stimulates foam cell like changes in rVSMCs. Prostaglandins \& other Lipid Mediators. 80, 165.

Linscheid, P., Seboek, D., Zulewski, H., Keller, U., Muller, B., 2005. Autocrine/paracirne role of inflammation-mediated calcitonin gene-related peptide and adrenomedullin expression in human adipose tissue. Endocrinol. 146, 2699-2708. 
Maslowska, M., Wang, H.W., Cianflone, K., 2005. Novel roles for acylation stimulating protein C3adesArg: a review of recent in vitro and in vivo evidence. Vitamin. Horm. 70, 309-32 .

Maslowska, M., Legakis, H., Assadi, F., Cianflone, K., 2006. Targeting the signaling pathway of acylation stimulating protein. J. Lipid Res. 47, 643-52.

Mastellos, D., Germenis, AE., Lambris, J.D., 2005. Complement: an inflammatory pathway fulfilling multiple roles at the interface of innate immunity and development. Curr. Drug Targets Inflamm. Allergy 4, 125-127.

Matthews, K.W., Mueller-Ortiz, SL., Wetsel, R.A., 2004. Carboxypeptidase N: a pleiotropic regulator of inflammation. Mol. Immunol. 40, 785-793.

McLean, R.H., Hoefnagel, D., 1980. Partial lipodystrophy and familial C3 deficiency. Hum. Hered. 30, 149-154.

Miner, J.L., 2004. The adipocyte as an endocrine cell. J Anim Sci. 82, 935-941.

Murray, I., Sniderman, A.D., Cianflone, K., 1999. Mice lacking acylation stimulating protein (ASP) have delayed postprandial tryglyceride clearance. J. Lipid Res. 40, 16711676.

Okuno, M., Arimoto, E., Nishizuka, M., Nishihara, T., Imagawa, M., 2002. Isolation of upor down-regulated genes in PPAR $\gamma$-expressing $\mathrm{NIH}-3 \mathrm{~T} 3$ cells during differentiation into adipocytes. FEBS Letters 519, 108-112.

Paglialunga, S., Fisette, A., Yan, Y., Deshaies, Y., Brouillette, J-F., Pekna, M., Cianflone, K., 2008. Acylation-stimulating protein deficiency and altered adipose tissue in alternative complement pathway knockout mice. Am. J. Physiol. Endocrinol. Metab. 294, E521-E529.

Peake, P.W., O'Grady, S., Pussell, B.A., Charlesworth, J.A., 1997. Detection and quantification of the control proteins of the alternative pathway of complement in 3T3-L1 adipocytes. Eur. J. Clin. Invest. 27, 922-927. 
Peake, P.W., Shen, Y., Walther, A., Charlesworth, J.A., 2008. Adiponectin binds C1q and activates the classical pathway of comlement. Biochem. Biophys. Res. Commun. $367,560-565$.

Rink, C., Roy, S., Khanna, S., Rink, T., Bagchi, D., Sen, C., 2007. Transcriptome of the subcutaneous adipose tissue in response to oral supplementation of type $2 \operatorname{Lepr}^{\text {db }}$ obese diabetic mice with niacin-bound chromium. Physiol. Genomics 27, 370-379.

Sato, T., Miwa, T., Akatsu, H., Matsukawa, N., Obata, K., Okada, N., Campbell, W., Okada, $H_{\text {., }}$ 2000. Pro-carboxypeptidase $\mathrm{R}$ is an acute phase protein in the mouse, whereas carboxypeptidase N is not. J. Immunol. 165, 1053-1058.

Schäffler, A., Schölmerich, J., Salzberger, B., 2007. Adipose tissue as an immunological organ: Toll-like receptors, C1q/TNFs and CTRPs. Trends Immunol. 28, 393-399.

Schenkein, H.A., Ruddy, S., 1981. The role of immunoglobulins in alternative pathway activation by zymosan. The effect of $\lg G$ on the kinetics of the alternative pathway. J. Immunol. 126, 11-15.

Seboek, D., Linscheid, P., Zulewski, H., Langer, I., Christ-Crain, M., Keller, U., Muller. 2004. Somatostatin is expressed and secreted by human adipose tissue upon infection and inflammation. J. Endocrinol. Metab. 89, 4833-4839.

Sissons, J.G., West, R.J., Fallows, J., Williams, D.G., Boucher, B.J., Amos, N., Peters, D.K., 1976. The complement abnormalities of lipodystrophy. N. Engl. J. Med. 294, 461465.

Spitzer, D., Mitchell, L.M., Atkinson, J.P., Hourcade, D.E., 2007. Properdin can initiate complement activation by binding specific target surfaces and providing a platform for de novo convertase assembly. J. Immunol. 179, 2600-2608.

Stover, C.M., Luckett, J., Echtenacher, B., Figgitt, S., Dupont, A., Brown, J., Maennel, D., Schwaeble, W., 2008. Properdin plays a protective role in polymicrobial septic peritonitis. J. Immunol. 180, 3313-3318. 
Su, A.I., Cooke, M.P., Ching, K.A., Hakak, Y., Walker, J.R., Wiltshire, T., Orth, A.P., Vega, R.G., Sapinoso, L.M., Moqrich, A., Patapoutian, A., Hampton, G.M., Schultz, P.G., Hogenesch, J.B., 2002. Large-scale analysis of the human and mouse transcriptomes.

Proc. Natl. Acad. Sci. USA 99, 4465-4470.

Tilg, H., Moschen, A., 2006. Adipocytokines: mediators linking adipose tissue, inflammation and immunity. Nature Rev. Immunol. 6, 772-783.

Trayhurn, P., 2005. Endocrine and signalling role of adipose tissue: new perspectives on fat. Acta Physiol. Scand. 184, 285-293.

Verdeguer, F., Castro, C., Kubicek. M., Pla, D., Vila-Caballer, M., Vinué, Á., Civeira, F., Pocoví. M., Calvete, J.J., Andrés, V., 2007. Complement regulation in murine and human hypercholesterolemia and role in the control of macrophage and smooth muscle cell proliferation. Cardiovasc. Res. 76, 340-350.

Vik D.P., Amiguet, P., Moffat, G.J., Fey, M., Amiguet-Barras, F., Wetsel, R.A., Tack, B.F., 1991. Structural features of the human C3 gene: intron/exon organization, transcriptional start site, and promoter region sequence. Biochemistry 30, 1080-1085. Wellen, K.E., Hotamisligil, G.S., 2005. Inflammation, stress, and diabetes. J.Clin. Invest. $115,1111-1119$.

White, R.T., Damm, D., Hancock, N., Rosen, B.S. , Lowell, B.b., Usher, P., Flier, J.S., Spiegelman, B.M., 1992. Human adipsin is identical to complement factor D and is expressed at high levels in adipose tissue. J. Biol. Chem. 267, 9210-9213.

Wilsie, L.C., Chanchani, S., Navaratna, D., Orlando, R., 2005. Cell surface heparan sulfate proteoglycans contribute to intracellular lipid accumulation in adipocytes. Lipids Health Dis. 4, 2-16.

Xu, W., Berger, S.P., Trouw , L.A., de Boer, H.C., Schlagwein, N., Mutsaers, C., Daha, M.R., van Kooten, C., 2008. Properdin binds to late apoptotic and necrotic cells independently of $\mathrm{C} 3 \mathrm{~b}$ and regulates alternative pathway complement activation. J. 
Immunol. 180, 7613-7621. 


\section{Legends}

\section{Figure 1}

Schematic representation of complement activation (without regulators)

C3a, encircled, is the precursor of C3adesarg.

\section{Figure 2}

Metabolic pathways in the adipocyte and influence of C3desArg (ASP, acylation stimulating protein). IP3 is inositoltriphosphate

\section{Figure 3}

Partial amino acid sequence alignment of human and mouse thrombospondin (TSP1) and properdin.

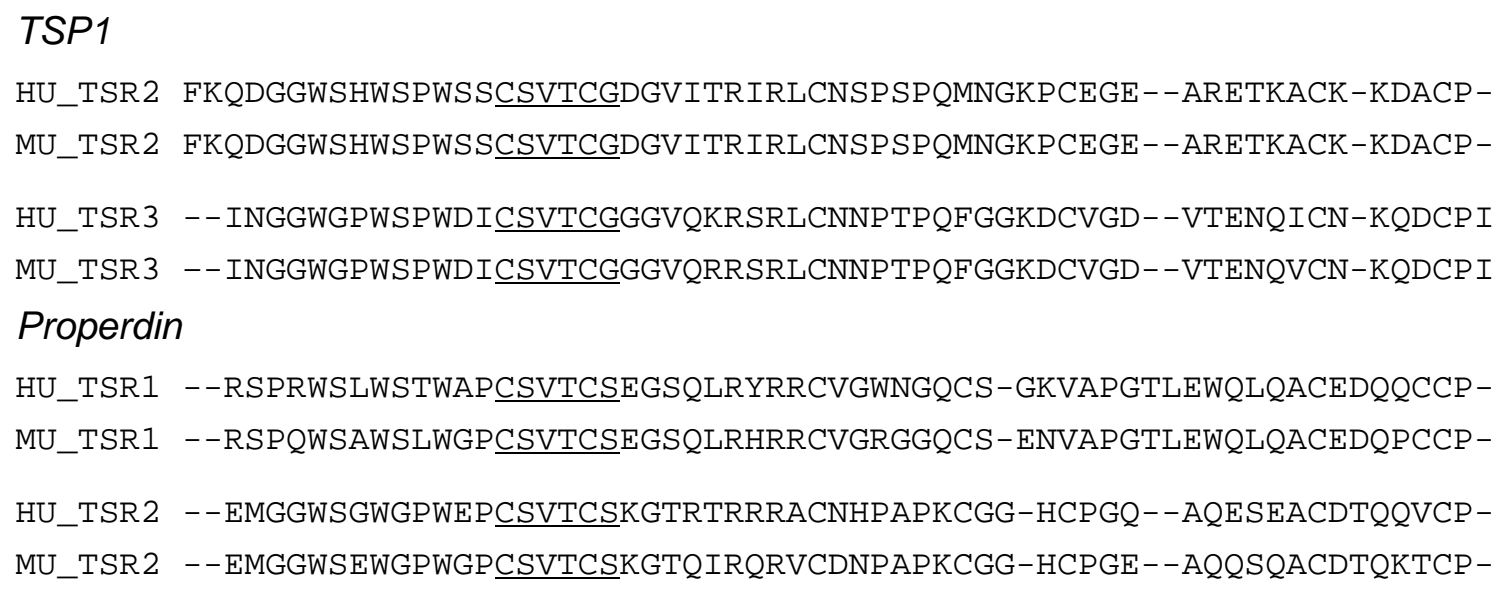

Over a stretch of 169 amino acids, properdin is structurally related to TSP1. In TSP1, this sequence encodes three thrombospondin repeats, TSRs, of which TSR2\&TSR3 have high similarity to $\mathrm{N}$-terminal sequences (TSR1\&TSR2) of properdin. Within these repeats in TSP1, a peptide, CSVTCG, mediates CD36 binding. This sequence is conserved in TSR1\&TSR2 of human and mouse properdin as CSVTCS. 


\section{Figure 4}

Adipocytes and adipose tissue mast cells express properdin

Mouse inguinal adipose tissue was processed and stained for mast cell tryptase (A) and properdin (B) (as described in Stover et al., 2008). Cell nuclei in the overlay (C) are stained blue with a DNA labeling dye, DAPI. The overlay shows properdin positivity (green) for adipocytes (along the polyhedral signet ring outline), as well as properdin (green) and tryptase (red) positivity for a resident mast cell. Co-localisation appears yellow (C).

Table 1: Complement molecule repertoire of adipose tissue (in non-obese, non-hypoxic state)

\begin{tabular}{|l|l|l|}
\hline Complement molecules & Technique and template & Reference \\
\hline Adipsin/Factor D & $\begin{array}{l}\text { Northern blot, human } \\
\text { subcutaneous fat tissue }\end{array}$ & $\begin{array}{l}\text { White et al., } \\
1992\end{array}$ \\
\hline $\begin{array}{l}\text { C6, Factor I, C3aR, C3, C1q, CR2, C1r, Factor } \\
\text { H, C4 }\end{array}$ & $\begin{array}{l}\text { Microarray, mouse } \\
\text { inguinal adipose tissue }\end{array}$ & $\begin{array}{l}\text { Koza et al., } \\
2006\end{array}$ \\
\hline $\begin{array}{l}\text { C4, Factor B, C5aR, C1s, properdin, C1r, C6, } \\
\text { CR2, Factor H, C2, CR1, C8, C3aR, Factor D }\end{array}$ & $\begin{array}{l}\text { Microarray, mouse } \\
\text { subcutaneous fat tissue }\end{array}$ & $\begin{array}{l}\text { Rink et al., } \\
2006\end{array}$ \\
\hline Factor D, B, C3, CR1, Factor H, properdin & $\begin{array}{l}\text { RT-PCR, mouse 3T3-L1 } \\
\text { cells }\end{array}$ & $\begin{array}{l}\text { Peake et al., } \\
1997\end{array}$ \\
\hline C1q, C1r, C2 & $\begin{array}{l}\text { Microarray, mouse } \\
\text { adipose tissue }\end{array}$ & Su et al., 2002 \\
\hline
\end{tabular}




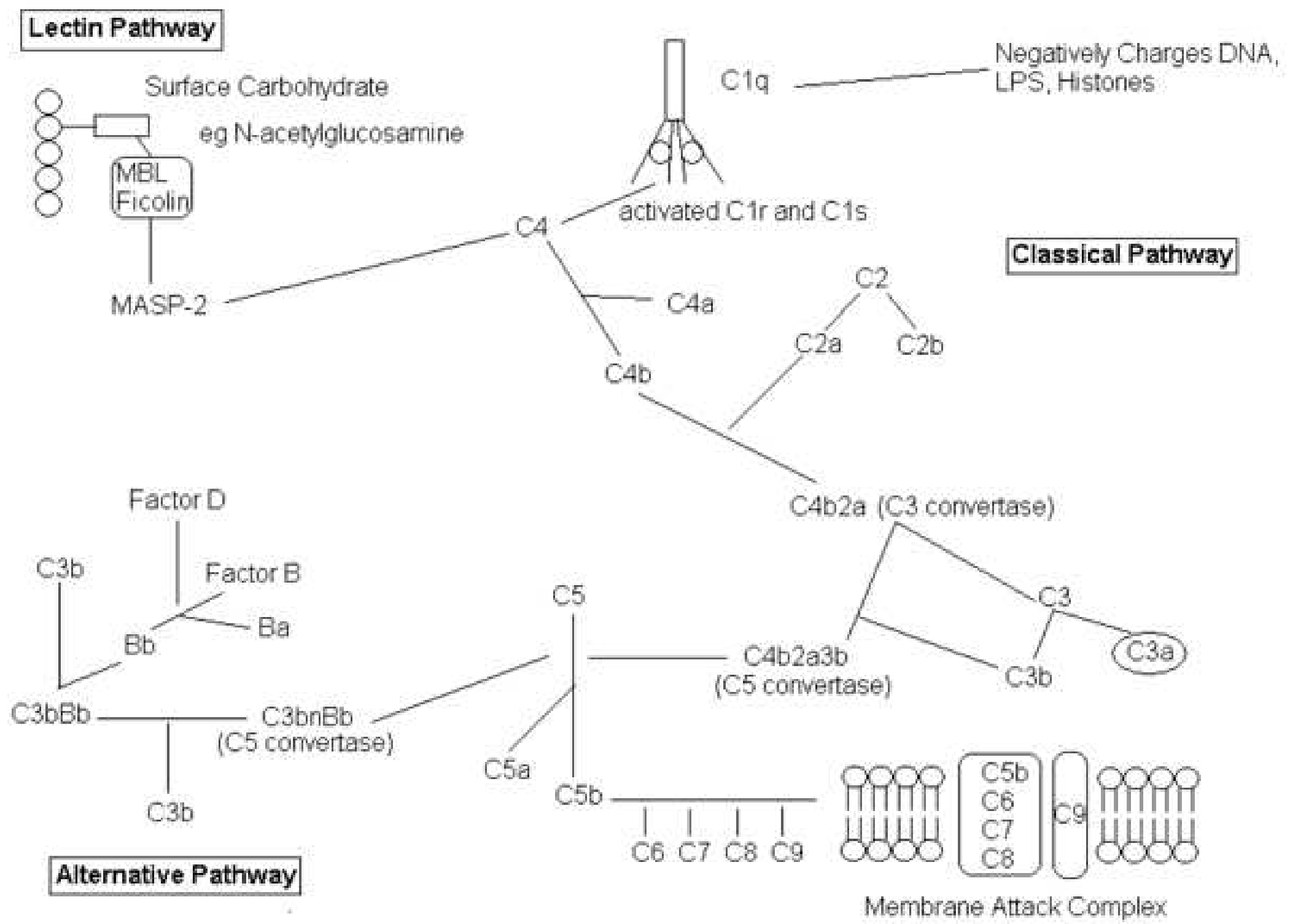




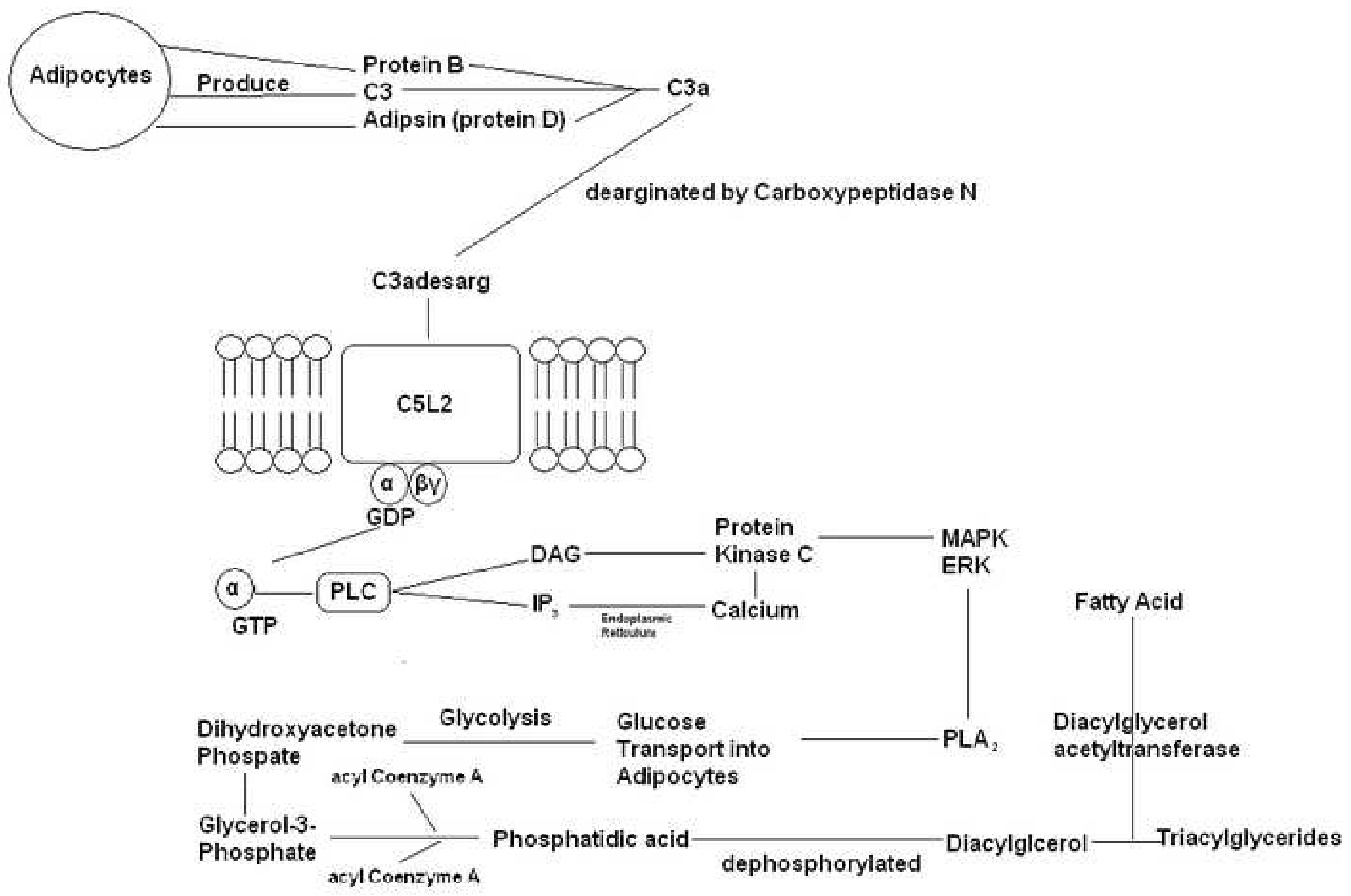


Click here to download high resolution image

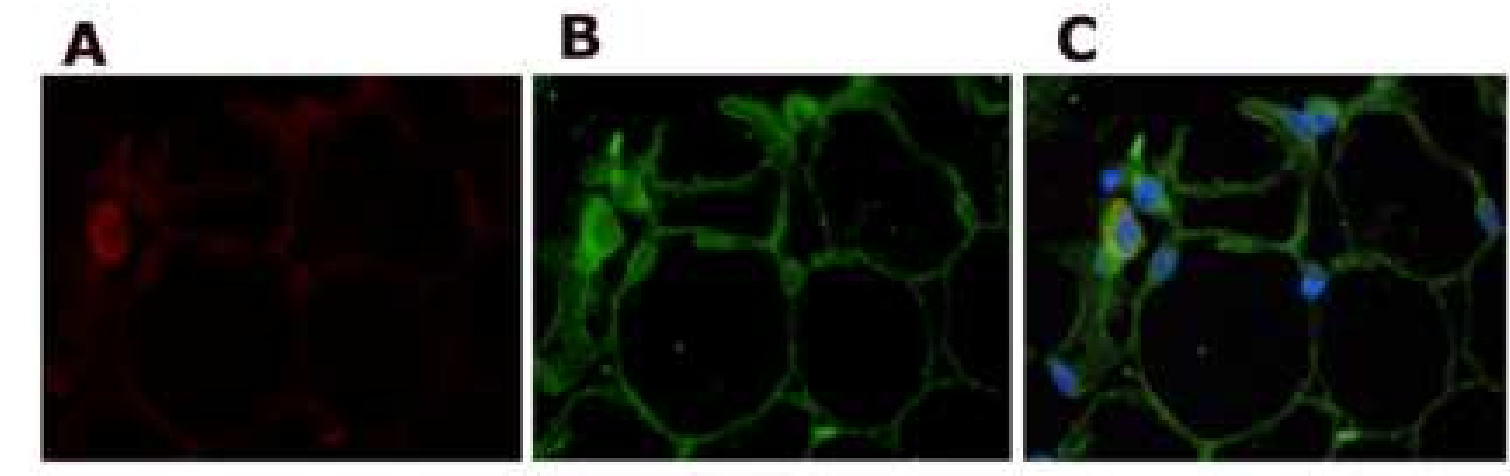

